\title{
Association between Diabetes Mellitus and Fatty Liver Based on Ultrasonography Screening in the World's Highest Cholangiocarcinoma Incidence Region, Northeast Thailand
}

\author{
Kavin Thinkhamrop ${ }^{1}$, Narong Khuntikeo ${ }^{2}$, Pichai Phonjitt ${ }^{2}$, Nittaya Chamadol ${ }^{3}$, \\ Bandit Thinkhamrop ${ }^{4}$, Malcolm Anthony Moore ${ }^{5}$, Supannee Promthet ${ }^{5 *}$
}

\begin{abstract}
Fatty liver disease (FLD) can be a precondition for other liver pathology including cholangiocarcinoma (CCA). Diabetes mellitus (DM) has been suggested in some studies to be a risk factor for FLD as well as cancers, including cholangiocellular carcinoma; however, there are currently very few studies on FLD in DM subjects, although the rate of FLD continues to increase annually. To determine the association between DM and FLD ultrasonographic data were analyzed from the Cholangiocarcinoma Screening and Care Program (CASCAP), in northeast Thailand. DM was reported by the subjects based on the CASCAP health questionnaire. Factors that were associated with FLD were determined by prevalence, odds ratio (ORs) and its $95 \%$ confidence intervals (CIs) using multiple logistic regression. There were 45,263 subjects with a mean age of $53.46( \pm 9.25)$ years. FLD was found in $36.3 \%$ of DM subjects but only in $20.7 \%$ of non-DM subjects. The association between DM and FLD was adjusted for all other factors including gender, age, education level, relatives diagnosed with CCA, smoking, alcohol consumption, and hepatitis B and C. The risk of DM in subjects having FLD was highly significant compared with the non-DM subjects (OR 2.13; 95\% CI: 1.92 to 2.35; p-value < 0.001 ). Thus DM is significantly associated with FLD which in turn may facilitate the development of several diseases including CCA. DM should be taken into consideration in future ultrasonic investigations of FLD and CCA.
\end{abstract}

Keywords: Fatty liver - diabetes mellitus - ultrasonography - screening - Thailand

Asian Pac J Cancer Prev, 16 (9), 3931-3936

\section{Introduction}

Fatty liver disease (FLD) may be present in over 30\% of general population in Western countries (Browning et al., 2004; Loomba and Sanyal, 2013) whereas the ranges of prevalence from $6 \%$ up to $25 \%$ in Asian populations (Fan, 2007), with high rates especially in males. The prevalence of FLD has increased in the general population in Japan, there was $41 \%$ in males and $17.7 \%$ in females (Eguchi et al., 2012).

FLD is classified as alcoholic fatty liver disease (AFLD) (O'Shea et al., 2010) and non-alcoholic fatty liver disease (NAFLD), both can be a precondition for other liver pathology including cholangiocarcinoma (CCA) (Shaib et al., 2005; Welzel et al., 2007a; Welzel et al., 2007b). There were many causes of FLD include gender, age, body mass index (BMI), smoking status, alcohol drinking, hepatitis $\mathrm{B}$ and/or $\mathrm{C}$ virus, hypertension, including diabetes mellitus (DM) (Fan et al., 2005; Cheung and Sanyal, 2008; Leite et al., 2009; Kim et al.,
2011; Hu et al., 2012; Wong et al., 2012; Yan et al., 2013; Xiao et al., 2014). DM patients were high prevalence of ultrasonographic FLD (Leite et al., 2009) and DM also link to several types of cancer including cholangiocarcinoma (CCA) (Jing et al., 2012). CCA was usually fatal, northeast Thailand-very important common cancer, although the rate of FLD continues to increase annually.

The prevalence of DM among adults will be increase $69 \%$ between 2010 and 2030 in developing countries (Shaw et al., 2010). It is an established risk factor for liver cancer, including CCA (Adami et al., 1996; Hsing et al., 2008; Shebl et al., 2011; Mohammad-Alizadeh et al., 2012; Palmer and Patel, 2012; Wu et al., 2013).

Diabetes is common in Thailand (9.6\% of Thai people) (Aekplakorn et al., 2003). The incidence of type 1 DM in children in northeast Thailand was only 1.27 per 100,000 in 2005 (Deerochanawong and Ferrario, 2013). DM has been suggested in some studies to be a risk factor for FLD. For example, the result of study in 1,069 hospitalized patients with type 2 DM conducted by Yan et al. (2013)

${ }^{1}$ Doctor of Public Health Program, ${ }^{5}$ Department of Epidemiology, ${ }^{4}$ Department of Biostatistics and Demography, Faculty of Public Health, ${ }^{2}$ Department of Surgery, ${ }^{3}$ Department of Radiology, Faculty of Medicine, Khon Kaen University, Thailand *For correspondence: supannee@kku.ac.th 


\section{Kavin Thinkhamrop et al}

has been found the rate of FLD based on ultrasonography was $56.7 \%$, and also study of NAFLD in patients with type 2 DM conducted by Leite et al. (2009) shown the prevalence of ultrasonographic NAFLD was $69.4 \%$ as well as the study was to investigate associations between combinations of BMI categories plus NAFLD and DM among Korean adults conducted by Kim et al. (2011) have been show the prevalence of NAFLD was highest in subjects with DM $(87.9 \%)$.

There are currently very few studies on FLD in DM subjects. This is particularly true for the northeast of Thailand in spite of the fact that CCA has its highest incidence worldwide in this area and FLD is an associated factor.

This study aims at determining the association between DM, FLD and CCA in North-East Thailand.

\section{Materials and Methods}

\section{Study design}

This cohort study was conducted at 9 tertiary care hospitals in northeast Thailand. They are the main public hospitals in the region and part of the Cholangiocarcinoma Screening and Care Program (CASCAP, www.cascap. in.th). These hospitals provided care for most of the CCA patients in the region. All CCA patients clinically diagnosed since February 2014 were enrolled. Patients were diagnosed and treated according to routine, real world clinical practice of participating hospitals. All patients were followed and provided with either clinical or palliative care depending on the stage of the disease. Treatment outcomes were recorded. The follow-up was, unless scheduled otherwise, every 3 to 6 months depending on the patient's condition. The present paper selected all subjects enrolled in the CASCAP database from 2013 - 2014. Subjects with incomplete information of data were excluded. A total of 45,263 subjects were included in the analysis.

\section{Study population}

A total of 84,435 subjects agreed to participate in the CASCAP study. All were resident in the northeast of Thailand. Figure 1 shows the selection process used to determine the 45,263 subjects included in this study.

\section{Factors used to characterize the subjects}

Demographic characteristics of DM and non-DM subjects were gender, age, education levels, occupation, relatives with diagnosed $\mathrm{CCA}$, smoking, degree of alcohol consumption, hepatitis $\mathrm{B}$ and/or $\mathrm{C}$ infection, and hypertension. These factors are considered biologically and sociologically relevant or show a univariate relationship with FLD.

\section{Ethical consideration}

This study was conduct according to the International Conference of Harmonization (ICH), Good Clinical Practice (GCP) guidelines and the Declaration of Helsinki. The final study protocol and the final version of the Written Informed Consent were approved by Khon Kaen University Ethics Committee (HE581015).

\section{Data analysis}

Demographic characteristics of DM and non-DM subjects were described using frequency and percentage for categorical data such as gender, age group, education levels, occupation, relatives with diagnosed CCA, smoking, degree of alcohol consumption, have had hepatitis $\mathrm{B}$ and $\mathrm{C}$, and hypertension. To describe continuous data such as the age of subjects mean, standard deviation, median, minimum, and maximum were used.

Prevalence of FLD was calculated and percentage of the prevalence was computed based on a normal approximation to the binomial distribution. Simple logistic regression was used to investigate factors associated with FLD, as determined by crude odd ratio (OR) and their $95 \%$ confidence interval (CI) for each factor.

Table 1. Demographic Characteristics of Subjects Presented as Number and Percentage. Missing Values were Present for some Individuals. CCA Indicates Cholangiocarcinoma

\begin{tabular}{|c|c|c|}
\hline Characteristics & Number & Percent \\
\hline \multicolumn{3}{|l|}{ Gender $(n=45,100)$} \\
\hline Male & 19,055 & 42.3 \\
\hline Female & 26,045 & 57.7 \\
\hline \multicolumn{3}{|l|}{ Age in years $(n=45,263)$} \\
\hline 40 to 44 & 8,481 & 18.7 \\
\hline 45 to 49 & 9,275 & 20.5 \\
\hline 50 to 54 & 8,831 & 19.5 \\
\hline 55 to 59 & 7,373 & 16.3 \\
\hline $60+$ & 11,303 & 25 \\
\hline Mean $( \pm \mathrm{SD})$ & $3.46( \pm 9.25)$ & \\
\hline Median (Min : Max) & $52(40: 99)$ & \\
\hline \multicolumn{3}{|l|}{ Education level $(n=43,554)$} \\
\hline None & 407 & 0.9 \\
\hline Primary & 32,410 & 74.4 \\
\hline Secondary & 7,204 & 16.5 \\
\hline Certificate & 665 & 1.5 \\
\hline Bachelor & 2,130 & 4.9 \\
\hline Higher than Bachelor & 738 & 1.7 \\
\hline \multicolumn{3}{|l|}{ Occupation $(n=45,263)$} \\
\hline Unemployed & 3,163 & 7 \\
\hline Farmer & 35,091 & 77.5 \\
\hline Labor & 2,380 & 5.3 \\
\hline Own business & 1,519 & 3.4 \\
\hline Government official/State enterprises & 3,110 & 6.9 \\
\hline \multicolumn{3}{|l|}{ Relatives with diagnosed CCA $(\mathrm{n}=43,481)$} \\
\hline No & 28,220 & 64.9 \\
\hline Yes & 15,261 & 35.1 \\
\hline \multicolumn{3}{|l|}{ Smoking $(\mathrm{n}=43,167)$} \\
\hline No & 33,214 & 76.9 \\
\hline Yes, current or previous & 9,953 & 23.1 \\
\hline \multicolumn{3}{|l|}{ Alcohol consumption $(n=43,518)$} \\
\hline No & 24,463 & 56.2 \\
\hline Yes, current or previous & 19,055 & 43.8 \\
\hline \multicolumn{3}{|l|}{ Hepatitis B infection $(n=45,263)$} \\
\hline No & 44,361 & 98 \\
\hline Yes & 902 & 2 \\
\hline \multicolumn{3}{|l|}{ Hepatitis C infection $(n=45,263)$} \\
\hline No & 45,196 & 99.8 \\
\hline Yes & 67 & 0.2 \\
\hline \multicolumn{3}{|l|}{ Hypertension $(\mathrm{n}=45,263)$} \\
\hline No & 43,956 & 97.1 \\
\hline Yes & 1,307 & 2.9 \\
\hline
\end{tabular}


Multiple logistic regression was used to investigate factors associated with FLD, as determined by adjusted ORs and their 95\% CIs. This analysis was adjusted for the factors indicated above.

All test statistics were two-tailed and a p-value of less than 0.05 was considered statistically significant. All analyses were performed by using STATA version 10 (StataCorp, 2007).

\section{Results}

Demographic characteristics

There were 45,263 subjects with a mean age of 53.46 $( \pm 9.25)$ ranging from 40 to 99 years. More than half were

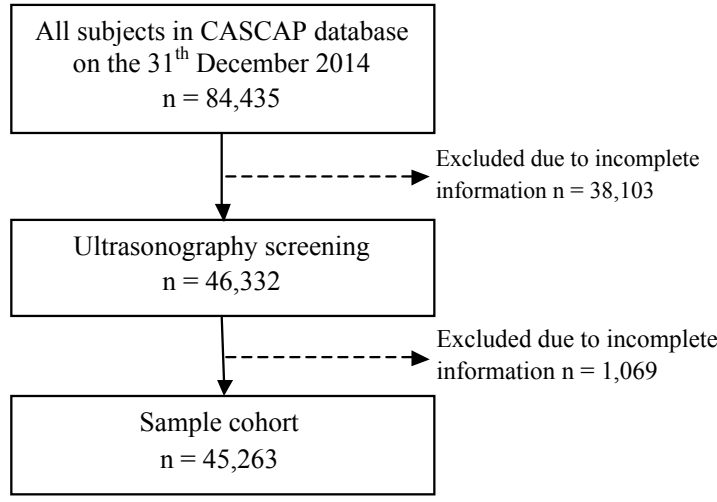

Figure 1. Sample Selection Process

Table 2. Prevalence of Fatty Liver Disease (FLD) and Odds Ratio (OR) of Factors that were Associated with FLD and Their $95 \%$ Confidence Intervals (CI) for Each Factor Using Simple Logistic Regression

\begin{tabular}{|c|c|c|c|c|c|}
\hline Factors & Number & $\%$ FLD & Crude OR & $95 \% \mathrm{CI}$ & p-value \\
\hline Over all & 45,263 & 21.3 & $\mathrm{NA}^{*}$ & $\mathrm{NA}^{*}$ & NA* \\
\hline Diabetes mellitus infection & & & & & $<0.001$ \\
\hline No & 43,438 & 20.7 & 1 & & \\
\hline Yes & 1,825 & 36.3 & 2.19 & $1.98-2.41$ & \\
\hline Gender & & & & & $<0.001$ \\
\hline Male & 19,055 & 18.7 & 1 & & \\
\hline Female & 26,045 & 23.1 & 1.31 & $1.25-1.37$ & \\
\hline Age increase every 1 year & 45,263 & NA* & 1 & $1.00-1.00$ & 0.393 \\
\hline Age in years & & & & & $<0.001$ \\
\hline 40 to 44 & 8,481 & 18.6 & 1 & & \\
\hline 45 to 49 & 9,275 & 20.9 & 1.16 & $1.07-1.24$ & \\
\hline 50 to 54 & 8,831 & 23.8 & 1.37 & $1.27-1.47$ & \\
\hline 55 to 59 & 7,373 & 24.4 & 1.42 & $1.31-1.53$ & \\
\hline $60+$ & 11,303 & 19.7 & 1.07 & $1.00-1.15$ & \\
\hline Education level & & & & & $<0.001$ \\
\hline None & 407 & 16.5 & 1 & & \\
\hline Primary & 32,410 & 20.7 & 1.33 & $1.02-1.73$ & \\
\hline Secondary & 7,204 & 21.3 & 1.37 & $1.05-1.80$ & \\
\hline Certificate & 665 & 26.8 & 1.85 & $1.36-2.54$ & \\
\hline Bachelor & 2,130 & 25.5 & 1.74 & $1.31-2.30$ & \\
\hline Higher than Bachelor & 738 & 30.8 & 2.25 & $1.66-3.06$ & \\
\hline Occupation & & & & & $<0.001$ \\
\hline Unemployed & 3,163 & 22.4 & 1 & & \\
\hline Farmer & 35,091 & 20.5 & 0.89 & $0.82-0.98$ & \\
\hline Labor & 2,380 & 21.1 & 0.93 & $0.82-1.06$ & \\
\hline Own business & 1,519 & 25.1 & 1.16 & $1.01-1.34$ & \\
\hline Government official/State enterprise & 3,110 & 27.5 & 1.32 & $1.18-1.48$ & \\
\hline Relatives with diagnosed CCA & & & & & 0.002 \\
\hline No & 28,220 & 20.8 & 1 & & \\
\hline Yes & 15,261 & 22.1 & 1.08 & $1.03-1.13$ & \\
\hline Smoking & & & & & $<0.001$ \\
\hline No & 33,214 & 22.4 & 1 & & \\
\hline Yes, current or previous & 9,953 & 17.7 & 0.75 & $0.70-0.79$ & \\
\hline Alcohol consumption & & & & & $<0.001$ \\
\hline No & 24,463 & 22.2 & 1 & & \\
\hline Yes, current or previous & 19,055 & 20.2 & 0.88 & $0.84-0.93$ & \\
\hline Hepatitis B infection & & & & & 0.211 \\
\hline No & 44,361 & 21.3 & 1 & & \\
\hline Yes & 902 & 19.6 & 0.9 & $0.76-1.06$ & \\
\hline Hepatitis C infection & & & & & 0.101 \\
\hline No & 45,196 & 21.3 & 1 & & \\
\hline Yes & 67 & 29.9 & 1.57 & $0.93-2.66$ & \\
\hline Hypertension & & & & & $<0.001$ \\
\hline No & 43,956 & 21.1 & 1 & & \\
\hline Yes & 1,307 & 28.2 & 1.47 & $1.30-1.66$ & \\
\hline
\end{tabular}

* Not applicable 
Kavin Thinkhamrop et al

Table 3. Adjusted Odds Ratio (Adj. OR) of Factors that Were Associated with Fatty Liver Disease (FLD) and Their 95\% Confidence Interval (CI) for Each Factor Adjusted for All Other Factors Using Multiple Logistic Regression

\begin{tabular}{|c|c|c|c|c|c|c|}
\hline Factors & Number & $\%$ FLD & Crude OR & Adj. OR & $95 \% \mathrm{CI}$ & p-value \\
\hline Diabetes mellitus infection & & & & & & $<0.001$ \\
\hline No & 43,438 & 20.7 & 1 & 1 & & \\
\hline Yes & 1,825 & 36.3 & 2.19 & 2.13 & $1.92-2.35$ & \\
\hline Gender & & & & & & $<0.001$ \\
\hline Male & 19,055 & 18.7 & 1 & 1 & & \\
\hline Female & 26,045 & 23.1 & 1.31 & 1.22 & $1.14-1.29$ & \\
\hline Age in years & & & & & & $<0.001$ \\
\hline 40 to 44 & 8,481 & 18.6 & 1 & 1 & & \\
\hline 45 to 49 & 9,275 & 20.9 & 1.16 & 1.16 & $1.07-1.25$ & \\
\hline 50 to 54 & 8,831 & 23.8 & 1.37 & 1.39 & $1.28-1.50$ & \\
\hline 55 to 59 & 7,373 & 24.4 & 1.42 & 1.44 & $1.33-1.56$ & \\
\hline $60+$ & 11,303 & 19.7 & 1.07 & 1.12 & $1.03-1.21$ & \\
\hline Education level & & & & & & $<0.001$ \\
\hline None & 407 & 16.5 & 1 & 1 & & \\
\hline Primary & 32,410 & 20.7 & 1.33 & 1.31 & $1.00-1.71$ & \\
\hline Secondary & 7,204 & 21.3 & 1.37 & 1.4 & $1.07-1.85$ & \\
\hline Certificate & 665 & 26.8 & 1.85 & 1.81 & $1.32-2.49$ & \\
\hline Bachelor & 2,130 & 25.5 & 1.74 & 1.77 & $1.33-2.35$ & \\
\hline Higher than Bachelor & 738 & 30.8 & 2.25 & 2.27 & $1.66-3.10$ & \\
\hline Relatives with diagnosed CCA & & & & & & 0.006 \\
\hline No & 28,220 & 20.8 & 1 & 1 & & \\
\hline Yes & 15,261 & 22.1 & 1.08 & 1.07 & $1.02-1.12$ & \\
\hline Smoking & & & & & & $<0.001$ \\
\hline No & 33,214 & 22.4 & 1 & 1 & & \\
\hline Yes, current or previous & 9,953 & 17.7 & 0.75 & 0.85 & $0.79-0.91$ & \\
\hline Alcohol consumption & & & & & & 0.409 \\
\hline No & 24,463 & 22.2 & 1 & 1 & & \\
\hline Yes, current or previous & 19,055 & 20.2 & 0.88 & 1.02 & $0.97-1.08$ & \\
\hline Hepatitis B infection & & & & & & 0.262 \\
\hline No & 44,361 & 21.3 & 1 & 1 & & \\
\hline Yes & 902 & 19.6 & 0.9 & 0.91 & $0.77-1.07$ & \\
\hline Hepatitis C infection & & & & & & 0.088 \\
\hline No & 45,196 & 21.3 & 1 & 1 & & \\
\hline Yes & 67 & 29.9 & 1.57 & 1.59 & $0.93-2.70$ & \\
\hline
\end{tabular}

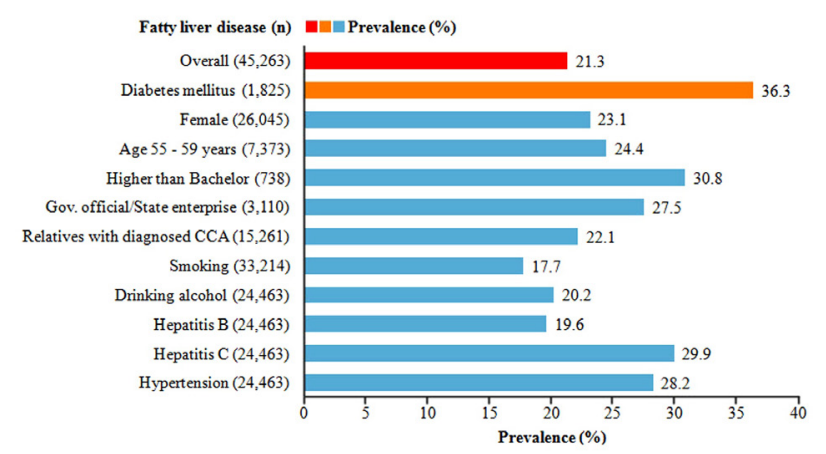

Figure 2. Prevalence of FLD Across Selected SubGroup

female $(57.7 \%)$, and most had finished primary school $(74.4 \%)$ and worked as farmers $(77.5 \%)$ (Table 1$)$.

From 45,263 subjects, the overall prevalence of FLD was $21.3 \%$. FLD was found in $36.3 \%$ of DM subjects but only in $20.7 \%$ of non-DM subjects. The association between DM and FLD from a crude analysis using simple logistic regression was highly significant compared with the non-DM subjects $(\mathrm{OR}=2.19,95 \% \mathrm{CI}$ : 1.98 to 2.41 ; p-value <0.001) (Table 2 and Figure 2). Other factors showing a significant association were gender, with

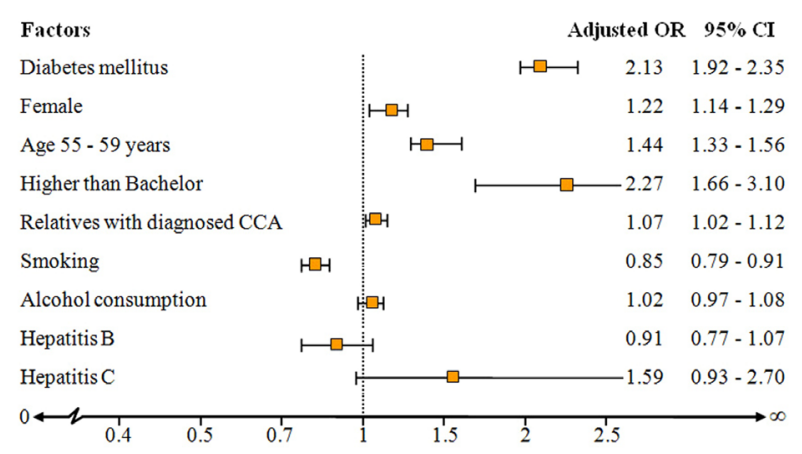

Figure 3. Factors Associated with FLD, Presented as Adjusted OR

females being more affected, age with a progressively increasing odds ratio until the age of 55-59, higher level of education meant a higher risk, occupation with sedentary occupations being more affected, relatives diagnosed with CCA, smoking, alcohol consumption and hypertension.

Using multiple logistic regression, the association between DM and FLD was adjusted for all other factors including gender, age, education level, relatives with diagnosed CCA, smoking, alcohol consumption, and hepatitis $\mathrm{B}$ and/or $\mathrm{C}$ infection. The risk of DM subjects 
having FLD remained highly significant compared with the non-DM subjects $(\mathrm{OR}=2.13,95 \% \mathrm{CI}$ : 1.92 to 2.35 ; p-value <0.001) (Table 3 and Figure 3 ). The other factors remained significant, although alcohol consumption switched to a positive association. Exclusion of occupation and hypertension lead to a higher odds ratio for the association between DM and FLD: the exclusion of other factors did not change the odds ratio.

\section{Discussion}

Prevalence of FLD among CCA risk groups in northeast Thailand was $21.3 \%$, which is lower than the prevalence of $42 \%$ in a healthy westernized Chinese population (Fung et al., 2014) and the prevalence of $27.3 \%$ of in South Korea (Jeong et al., 2013). We found that the prevalence of FLD was high among DM patients $(36.3 \%)$. Our results are consistent with a previous study of 400 type 2 diabetic patients in Brazil, which showed a high prevalence of associated NAFLD (Leite et al., 2009), and with a second study which found that the rate of FLD was $56.7 \%$ as diagnosed by ultrasound in 882 type $2 \mathrm{DM}$ patients from China (Yan et al., 2013).

For the factors that were associated with FLD, we found that the risk of DM subjects having FLD was highly significant (adjusted OR 2.13; 95\% CI: 1.92 2.35; p-value < 0.001). This is similar to a study which examined the factors associated with FLD in Shanghai employees and showed that type $2 \mathrm{DM}$ was a metabolic risk factor for FLD (Hu et al., 2012). It is also similar to a cross-sectional study among university faculty and staff in Chengdu, China, which showed that DM was associated with NAFLD (Shi et al., 2012).

From our crude analysis, we also found that alcohol consumption was a mildly protective factor, but when adjusted for all other factors, alcohol consumption switched to become a risk factor; although this risk was not significant being only $2 \%$ higher compared with non-alcohol consumers. We also found that as age increases, the risk of FLD also increased up until the age group 55-59, but declined at the age of $60+$ years. This is similar to a study which determine the prevalence and risk factors of FLD in young and middle-aged population in Southwestern China and showed that the prevalence of FLD increased along with age and older age was related to FLD (Xiao et al., 2014).

Smoking scored as a protective factor against FLD (adjusted OR 0.85; 95\%CI: 0.79 - 0.91; p-value <0.001), which is not consistent with a previous study from Finland which showed that for young adults there was a strong association between these two factors (Suomela et al., 2014).

We also found that the risk of FDL increased with the level of education. The factor that was most associated with FLD was an education level higher than a bachelor's degree (adjusted OR 2.27; 95\%CI: 1.66 - 3.10; p-value < 0.001 ) which is consistent with a previous study in African Americans in the United States which found that education was associated with NAFLD in this population (Foster et al., 2013). This may be related to the different eating habits of socio-economically better of graduates compared to, for example, the farming community. However, for other factors that was non-significant, our study found in hepatitis B and/or C infection.

Our data on FLD among DM patients highlight a health problem that cannot be ignored. Surveillance and early diagnosis would make possible the implementation of measures aimed at achieving a substantial reduction in the prevalence of disease among DM patients. This study was conducted on a large, heterogeneous population across northeast of Thailand providing a cross section of cultural, socio-economic and environmental factors. It is a good representation of the population of northeast Thailand as a whole.

One potential problem with the study is that the demographic information was derived from subject questionnaires which are potentially biased as a medical diagnosis was not confirmed for $\mathrm{HB}, \mathrm{HC}$ and DM. This could lead to an underestimate as some subjects may not willing to disclose such results (Silva, 1999).

Despite these limitations, our data, based on a very large sample size, strongly indicate that DM is significantly associated with FLD, which in turn may facilitate the development of several diseases including CCA. Early detection of FLD by routine screening provides the possibility of reducing the prevalence of this disease in DM patients. Thus, DM should be taken into consideration in future ultrasonic investigations of FLD and CCA.

\section{Acknowledgements}

This work was supported by Khon Kaen University through CASCAP and the National Research Council of Thailand through the Medical Research Network of the Consortium of Thai Medical Schools. We would like to thanks Prof. Ross H. Andrews and Prof.Trevor N Petney for manuscript editing.

\section{References}

Adami HO, Chow WH, Nyren O, et al (1996). Excess risk of primary liver cancer in patients with diabetes mellitus. J Natl Cancer Inst, 88, 1472-7.

Aekplakorn W, Stolk RP, Neal B, et al (2003). The prevalence and management of diabetes in Thai adults: the international collaborative study of cardiovascular disease in Asia. Diabetes Care, 26, 2758-63.

Browning JD, Szczepaniak LS, Dobbins R, et al (2004). Prevalence of hepatic steatosis in an urban population in the United States: impact of ethnicity. Hepatol, 40, 1387-95.

Cheung O, Sanyal AJ (2008). Hepatitis C infection and nonalcoholic fatty liver disease. Clin Liver Dis, 12, 573-85.

Deerochanawong C, Ferrario A (2013). Diabetes management in Thailand: a literature review of the burden, costs, and outcomes. Global Health, 9, 11.

Eguchi Y, Hyogo H, Ono M, et al (2012). Prevalence and associated metabolic factors of nonalcoholic fatty liver disease in the general population from 2009 to 2010 in Japan: a multicenter large retrospective study.J Gastroenterol, $\mathbf{4 7}$, 586-95.

Fan JG (2007). [An introduction of strategies for the management of nonalcoholic fatty liver disease (NAFLD) recommended by Asia Pacific Working Party on NAFLD]. Zhonghua Gan 
Zang Bing Za Zhi, 15, 552-3.

Fan JG, Zhu J, Li XJ, et al (2005). Prevalence of and risk factors for fatty liver in a general population of Shanghai, China. $J$ Hepatol, 43, 508-14.

Foster T, Anania FA, Li D, et al (2013). The prevalence and clinical correlates of nonalcoholic fatty liver disease (NAFLD) in African Americans: the multiethnic study of atherosclerosis (MESA). Dig Dis Sci, 58, 2392-8.

Fung J, Lee CK, Chan M, et al (2014). High prevalence of nonalcoholic fatty liver disease in the Chinese - results from the Hong Kong liver health census. Liver Int. (in press).

Hsing AW, Zhang M, Rashid A, et al (2008). Hepatitis B and $\mathrm{C}$ virus infection and the risk of biliary tract cancer: a population-based study in China. Int J Cancer, 122, 1849-53.

$\mathrm{Hu}$ X, Huang Y, Bao Z, et al (2012). Prevalence and factors associated with nonalcoholic fatty liver disease in Shanghai work-units. BMC Gastroenterol, 12, 123.

Jeong EH, Jun DW, Cho YK, et al (2013). Regional prevalence of non-alcoholic fatty liver disease in Seoul and Gyeonggido, Korea. Clin Mol Hepatol, 19, 266-72.

Jing W, Jin G, Zhou X, et al (2012). Diabetes mellitus and increased risk of cholangiocarcinoma: a meta-analysis. Eur $J$ Cancer Prev, 21, 24-31.

Kim SH, Lee JW, Hwang HJ (2011). Associations between combinations of body mass index plus non-alcoholic fatty liver disease and diabetes mellitus among Korean adults. Asia Pac J Clin Nutr, 20, 14-20.

Leite NC, Salles GF, Araujo AL, et al (2009). Prevalence and associated factors of non-alcoholic fatty liver disease in patients with type-2 diabetes mellitus. Liver Int, 29, 113-9.

Loomba R, Sanyal AJ (2013). The global NAFLD epidemic. Nat Rev Gastroenterol Hepatol, 10, 686-90.

Mohammad-Alizadeh AH, Ghobakhlou M, Shalmani HM, et al (2012). Cholangiocarcinoma: an-eight-year experience in a tertiary-center in Iran. Asian Pac J Cancer Prev, 13, 5381-4.

O'Shea RS, Dasarathy S, McCullough AJ, et al (2010). Alcoholic liver disease. Hepatol, 51, 307-28.

Palmer WC, Patel T (2012). Are common factors involved in the pathogenesis of primary liver cancers? A meta-analysis of risk factors for intrahepatic cholangiocarcinoma. J Hepatol, 57, 69-76.

Shaib YH, El-Serag HB, Davila JA, et al (2005). Risk factors of intrahepatic cholangiocarcinoma in the United States: a case-control study. Gastroenterol, 128, 620-6.

Shaw JE, Sicree RA, Zimmet PZ (2010). Global estimates of the prevalence of diabetes for 2010 and 2030. Diabetes Res Clin Pract, 87, 4-14.

Shebl FM, Andreotti G, Meyer TE, et al (2011). Metabolic syndrome and insulin resistance in relation to biliary tract cancer and stone risks: a population-based study in Shanghai, China. Br J Cancer, 105, 1424-9.

Shi L, Liu ZW, Li Y, et al (2012). The prevalence of nonalcoholic fatty liver disease and its association with lifestyle/dietary habits among university faculty and staff in Chengdu. Biomed Environ Sci, 25, 383-91.

Silva IdS (1999). Cancer Epidemiology: Principles and Methods. IARC Press.

StataCorp LP (2007). Stata Release 10: User's guide. College Station TX: Stata Press.

Suomela E, Oikonen M, Virtanen J, et al (2014). Prevalence and determinants of fatty liver in normal-weight and overweight young adults. The Cardiovascular Risk in Young Finns Study. Ann Med, 1-7.

Welzel TM, Graubard BI, El-Serag HB, et al (2007a). Risk factors for intrahepatic and extrahepatic cholangiocarcinoma in the United States: a population-based case-control study. Clin Gastroenterol Hepatol, 5, 1221-8.
Welzel TM, Mellemkjaer L, Gloria G, et al (2007b). Risk factors for intrahepatic cholangiocarcinoma in a low-risk population: A nationwide case-control study. Int J Cancer, 120, 638-41.

Wong VW, Wong GL, Chu WC, et al (2012). Hepatitis B virus infection and fatty liver in the general population. J Hepatol, 56, 533-40.

Wu Y, Ahmed A, Kamal A (2013). Donor diabetes mellitus is an independent risk factor for graft loss in HCV positive but not HCV negative liver transplant recipients. Dig Dis Sci, 58, 574-8.

Xiao SJ, Fu GJ, Lv YL, et al (2014). Prevalence and risk factors of fatty liver disease in young and middle-aged population: one center study in Southwestern China. J Gastroenterol Hepatol, 29, 358-64.

Yan Y, Bian H, Xia MF, et al (2013). Liver disease spectrum in hospitalized type 2 diabetes and related risk factors analysis of non-alcoholic fatty liver disease. Zhonghua Yi Xиe Za Zhi, 93, 270-4 (in Chinese). 